Thromboangiitis obliterans is a nonatherosclerotic inflammatory occlusive vascular disease of unknown origin. In the absence of smoking, other risk factors, such as serum lipoprotein(a), must be considered in the pathogenesis of this disease. ${ }^{8}$ Even though 8 months after the operation the patient had returned to her normal activities, the prognosis will be influenced by the potential, and previously reported occurrence of thromboangiitis obliterans in the aorta-coronary saphenous vein grafts. ${ }^{9}$

\section{REFERENCES}

1. Amano J, Suzuki A. Coronary artery involvement in Takayasu's arteritis. J Thorac Cardiovase Surg 1991;102:554-60.

2. Pick RA, Glover MU, Vieweg MVR. Myocardial infarction in a young woman with isolated coronary arteritis. Chest 1992; 82:378-80.

3. Ohno H, Matsuda Y, Takashiba K, Hamada Y, Ebihara H,
Hyakuna E. Acute myocardial infarction in Buerger's disease. Am J Cardiol 1986;57:690-1.

4. Saphir O. Thromboangiitis obliterans of the coronary arteries and its relation to arteriosclerosis. Am Heart J 1936;12:521-35.

5. Mills JL, Porter JM. Thromboangiitis obliterans (Buerger's disease). In: Churg A, Churg J, Hunder GG, editors. Systemic vasculitis. Tokyo: Igaku-Shoin, 1991:229-39.

6. Goodman RM, Elian B, Mozes M, Deutsch B. Buerger's disease in Israel. Am J Med 1965;39:601-15.

7. Laslett LJ, Ikeda RM, Mason DT. Female adolescent Buerger's disease: objective documentation and therapeutic remission. Am Heart J 1981;102:452-6.

8. Takami S, Kubo M, Yamashita S, et al. High levels of serum lipoprotein(a) in patients with ischemic heart disease with normal coronary angiogram and thromboangiitis obliterans. Atherosclerosis 1995;112:253-60.

9. Lie JT. Thromboangiitis obliterans (Buerger's disease) in a saphenous vein arterial graft. Hum Pathol 1987;18:402-4.

\title{
ADDITIONAL POSTBYPASS ADMINISTRATION OF TRANEXAMIC ACID REDUCES BLOOD LOSS AFTER CARDIAC OPERATIONS
}

\author{
Junya Katoh, MD, Kouji Tsuchiya, MD, Wataru Sato, MD, Masato Nakajima, MD, and Yoshinao Iida, MD, \\ Yamanashi, Japan
}

Excessive bleeding after cardiac operations involving cardiopulmonary bypass (CPB), mostly a result of activated fibrinolysis and platelet dysfunction, remains a problem. Intraoperative administration of aprotinin significantly decreases postbypass blood loss; however, its use is limited because of complications such as inadequate heparinization during CPB and high cost. ${ }^{1}$ Alternatively, Karski and associates ${ }^{2}$ revealed that high-dose administration of tranexamic acid (TA) before CPB prevents excessive postoperative blood loss and reduces the need for blood transfusions. TA inhibits fibrinolysis by binding to the lysine binding site on plasminogen and plasmin, which is the binding site for fibrin.

It was reported that to counteract post-CPB fibrinolytic status and achieve hemostasis, high-dose TA administration was needed. ${ }^{3}$ The elimination half-life of TA is about 80 minutes. To maintain concentrations of TA in the

From the Department of Cardiovascular Surgery, Yamanashi Central Hospital, Kofu, Yamanashi, Japan.

Received for publication Oct. 8, 1996; accepted for publication Oct. 22, 1996.

Address for reprints: Junya Katoh, MD, Second Department of Surgery, Yamanashi Medical University, 1110 Shimokato, Tamaho-cho, Nakakoma-gun, Yamanashi, 409-38 Japan.

J Thorac Cardiovase Surg 1997;113:802-4

Copyright (c) 1997 by Mosby-Year Book, Inc.

$0022-5223 / 97 \$ 5.00+0 \quad \mathbf{1 2 / 5 4 / 7 8 7 6 7}$ blood during hemostasis after $\mathrm{CPB}$, we gave an additional half of the pre-CPB dose of TA during the post-CPB period. The objective of this study was to investigate whether an additional postbypass dose of TA affects post-CPB blood loss after cardiac operations:

Methods. Ninety-three patients undergoing either coronary artery bypass grafting or heart valve operation were studied with their informed consent. Approval for the study was received from our hospital's ethics review board. Only one cardiac surgeon (K. T.) was involved in the study. In this prospective, randomized trial, the patients were divided into three groups of equal size. Patient characteristics are summarized in Table I.

All patients received high-dose fentanyl anesthesia. Before CPB was established, heparin, $200 \mathrm{IU} / \mathrm{kg}$, was given intravenously to each patient. Additional heparin was added throughout CPB to maintain the activated clotting time at more than 400 seconds. Heparin was neutralized with protamine sulfate with the use of dose-response curves. Group TA-1 patients received an infusion of TA, $100 \mathrm{mg} / \mathrm{kg}$, intravenously, over 20 minutes soon after induction of anesthesia and before CPB. Group TA-2 patients received a 100 $\mathrm{mg} / \mathrm{kg}$ dose of TA, like the group TA-1 patients, and an additional TA dose of $50 \mathrm{mg} / \mathrm{kg}$ infused intravenously over 20 minutes soon after being weaned from CPB. Control group patients received conventional perioperative therapy. Red blood cells (RBCs) were transfused for a hemoglobin threshold of $75 \mathrm{gm} / \mathrm{L}$ or less. Mediastinal blood loss during the operation, but after discontinuation of CPB, and drain- 
Table I. Patient characteristics and surgical data

\begin{tabular}{lccc}
\hline & \multicolumn{3}{c}{ Group } \\
\cline { 2 - 4 } & $\begin{array}{c}\text { TA-1 } \\
(N=31)\end{array}$ & $\begin{array}{c}\text { TA-2 } \\
(N=31)\end{array}$ & $\begin{array}{c}\text { Control } \\
(N=31)\end{array}$ \\
\hline Age (yr) & $63.7 \pm 1.5$ & $62.9 \pm 1.7$ & $64.7 \pm 2.1$ \\
Weight (kg) & $59.1 \pm 2.6$ & $59.7 \pm 1.7$ & $61.9 \pm 1.6$ \\
Sex $\quad 22$ & 21 & 22 \\
$\quad$ Male & 9 & 10 & 9 \\
$\quad$ Female & 21 & 20 & 19 \\
CABG operations & 8 & 10 & 10 \\
Valve operations & 2 & 1 & 2 \\
Valve + CABG & & & \\
$\quad$ operations & $13.4 \pm 0.26$ & $13.5 \pm 0.25$ & $13.1 \pm 0.30$ \\
Preoperative Hb level $\quad$ (gm/L) & & & \\
CPB (min) & $79.8 \pm 3.7$ & $79.2 \pm 4.3$ & $77.0 \pm 3.8$ \\
ACC (min) & $42.3 \pm 3.2$ & $40.2 \pm 3.8$ & $38.8 \pm 3.2$ \\
Lowest rectal temperature & $29.8 \pm 0.29$ & $30.1 \pm 0.46$ & $30.0 \pm 0.34$ \\
$\quad$ during CPB ( $\left.{ }^{\circ} \mathrm{C}\right)$ & & & \\
\hline
\end{tabular}

Values are given as mean plus or minus the standard error of the mean. $C A B G$, Coronary artery bypass grafting; $H b$, hemoglobin; $A C C$, duration of aortic crossclamping.

age from mediastinal tubes for the first 24 hours after operation were measured.

Data are presented as means plus or minus the standard error of the mean. Comparisons of the mean values in the three groups were computed by one- and two-way analyses of variance.

Results. Patient characteristics were similar among groups, as shown in Table I. Table II summarizes the volume of post-CPB mediastinal blood loss, blood product requirements, and postoperative hemoglobin levels. Blood loss during the operation, but after CPB, in the TA-2 group was significantly lower than that in the TA-1 group (reduced $40 \%, p=0.0238$ ) and that in the control group (reduced 242\%, $p=0.0047$ ). Blood loss during the first 6 hours after operation was also significantly reduced compared with that in the TA-1 (reduced $42 \%, p=0.0050$ ) and the control group (reduced $134 \%, p=0.0003$ ). Blood loss from 6 to 24 hours in the TA-2 group was significantly lower than that in the control group (reduced 49\%, $p=0.0298$ ); however, there was no significance compared with the TA-1 group ( $p=0.1197)$.

During the first 24 hours after operation, there was a significant difference in blood loss in the TA-2 group compared with that in the TA-1 (reduced $25 \%, p=$ 0.0052 ) and the control groups (reduced $83 \%, p=$ 0.0020 ). Overall, the volume of blood loss monitored from the discontinuation of CPB until the completion of the operation and including the first 24 hours after the operation was significantly lower in the TA-2 group compared with that in the TA-1 group (reduced 31\%, $p=$ 0.0009 ) and the control group (reduced $152 \%, p=$ 0.0004 ). RBC units required for the three groups are compared in Table II. Three patients $(9.1 \%)$ required RBCs in the TA-2 group whereas 4 patients $(12.1 \%)$ in
Table II. Volume of post-CPB blood loss and blood requirements

\begin{tabular}{lccc}
\hline & \multicolumn{3}{c}{ Group } \\
\cline { 2 - 4 } & $\begin{array}{c}T A-1 \\
(N=31)\end{array}$ & $\begin{array}{c}T A-2 \\
(N=31)\end{array}$ & $\begin{array}{c}\text { Control } \\
(N=31)\end{array}$ \\
\hline $\begin{array}{l}\text { Blood loss during operation } \\
\quad 230 \pm 26.6\end{array}$ & $164 \pm 13.7$ & $561 \pm 134$ \\
after CPB (ml) & & & \\
Blood loss 0-6 hr (ml) & $126 \pm 13.5$ & $89.0 \pm 4.30$ & $208 \pm 30.5$ \\
Blood loss 6-24 hr (ml) & $141 \pm 8.35$ & $125 \pm 6.41$ & $185 \pm 26.2$ \\
Blood loss 0-24 hr (ml) & $268 \pm 18.7$ & $214 \pm 7.46$ & $392 \pm 54.9$ \\
Total blood loss (ml) $\dagger$ & $497 \pm 33.2$ & $378 \pm 15.2$ & $954 \pm 152$ \\
RBCs transfused (units) & $1.67 \pm 0.55$ & $1.16 \pm 0.42$ & $3.03 \pm 0.82$ \\
Postoperative Hb level & $10.9 \pm 0.17$ & $11.6 \pm 0.23$ & $11.0 \pm 0.30$ \\
$\quad(g m / L)$ & & &
\end{tabular}

Values are given as mean plus or minus the standard error of the mean. $\mathrm{Hb}$, Hemoglobin.

*Blood loss during operation after CPB is the volume of mediastinal blood loss during the operation, but after discontinuation of CPB.

TTotal blood loss is the volume of blood loss monitored from the discontinuation of CPB until the completion of the operation and including the first 24 hours after operation.

the TA-1 group and 10 patients $(30.3 \%)$ in the control group required RBCs. The number of transfused RBC units in the TA-2 group was significantly lower than that in the control group ( $p=0.0325$ ); however, there was no significant difference when compared with that in the TA-1 group. Operative death occurred in one patient in the TA-1 group as a result of myocardial infarction on the first postoperative day. There was no occurrence of stroke, pulmonary embolism, or deep venous thrombosis in any of the patients.

Comment. TA may improve hemostasis after operation by two mechanisms. First, TA inhibits post-CPB plasmininduced fibrinolysis by binding to the lysine binding site on plasmin and plasminogen. Second, TA inhibits plasmininduced platelet activation, consequently preserving platelet function. ${ }^{4}$ Concentrations of the TA administered before the $\mathrm{CPB}$ period may fall to less than half of the original level after CPB, because the elimination half-life of TA is about 80 minutes. To counteract a post-CPB fibrinolytic status, maintenance of the concentration of TA may be important. Therefore we hypothesized that an additional bolus dose of TA given soon after CPB might prevent reactivation of fibrinolysis and reinforce hemostasis.

The results proved our hypothesis was right. Blood loss in the TA-2 group was significantly reduced during each of the tested periods except from 6 to 24 hours after the operation. Furthermore, our study failed to show any increased incidence of perioperative thrombotic complications. We conclude that with additional administration of TA after CPB, blood loss after cardiac operations involving CPB will be safely reduced.

REFERENCES

1. Katsaros D, Petricevic M, Snow NJ, Woodhall DD, Bergen RV. Tranexamic acid reduces postbypass blood use: a double- 
blinded, prospective, randomized study of 210 patients. Ann Thorac Surg 1996;61:1131-5.

2. Karski JM, Teasdale SJ, Norman P, et al. Prevention of bleeding after cardiopulmonary bypass with high-dose tranexamic acid: double-blind, randomized clinical trial. J Thorac Cardiovasc Surg 1995;110:835-42.
3. Karski JM, Teasdale SJ, Norman PH, Carroll JA, Weisel RD, Glynn MFX. Prevention of postbypass bleeding with tranexamic acid and z-aminocaproic acid. J Cardiothorac Vasc Anesth 1993;7:431-5.

4. Soslou G, Horrow J, Brodsky I. Effect of tranexamic acid on platelet ADP during extracorporeal circulation. Am J Hematol 1991;38:113-9.

\title{
POSTOPERATIVE RIGHT VENTRICULAR DYSFUNCTION RELATED TO AN UNEXPECTED LATE FATAL COMPLICATION
}

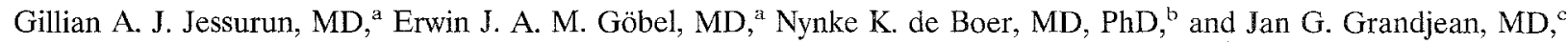
Groningen, The Netherlands

At present, aspirin is the first-line antithrombotic therapy for patients after coronary artery bypass grafting. The evaluation of postoperative coronary graft patency data suggests that dipyridamole in addition to low-dose aspirin does not improve aorta-coronary artery vein graft occlusion rate. Moreover, compared with aspirin, oral anticoagulants provided no benefit. ${ }^{1}$ In most clinics for heart surgery the antithrombotic postoperative regimen constitutes low-dose aspirin at discharge. Coumarins are reserved for those patients with artificial valves and moderate to severe areas of dyskinesia or akinesia after left ventricular infarctions or cardiomyopathy. However, we present a pertinent clinical observation that should alert clinicians to the necessity of optimal oral anticoagulation in patients with postoperative transient right ventricular dysfunction or the presence of right-sided cardiomyopathy.

A 41-year-old man had an anterior myocardial infarction 6 years before admission, for which he received thrombolysis. This was followed by a rescue percutaneous transluminal coronary angioplasty of the significant residual stenosis in the left anterior descending coronary artery. One year thereafter he underwent an angioplasty of the right coronary artery, with a second angioplasty for a restenosis of the right coronary artery. In June 1996 he was admitted with unstable angina pectoris. His chest symptoms remained refractory to treatment with intravenous heparin, high-dose nitroglycerin, aspirin, and a $\beta$-adrenergic blocker. Subsequently, coronary angiography re-

From University Hospital Groningen, Departments of Cardiolo$\mathrm{gy}^{\mathrm{a}}{ }^{\mathrm{C}}$ Pathology, ${ }^{\mathrm{b}}$ and Thoracic Surgery, ${ }^{\mathrm{c}}$ Groningen, The Netherlands.

Received for publication Sept. 20, 1996; accepted for publication Oct. 24, 1996.

Address for reprints: Gillian A. J. Jessurun, MD, Department of Cardiology, University Hospital Groningen, Hanzeplein 1, Groningen $9700 \mathrm{RB}$, The Netherlands.

J Thorac Cardiovasc Surg 1997;113:804-5

Copyright (C) 1997 by Mosby-Year Book, Inc.

$0022-5223 / 97 \$ 5.00+0 \quad \mathbf{1 2 / 5 4 / 7 8 9 2 8}$ vealed slightly impaired left ventricular function with hypokinesis of the anterior wall, a subtotal right coronary artery occlusion, significant left main stenosis, an $80 \%$ lesion of the circumflex coronary artery, and a $70 \%$ stenosis of the midportion of the left anterior descending coronary artery. Coronary artery bypass grafting was performed under clinically stable conditions. The left thoracic artery was anastomosed to the left anterior descending coronary artery. The right thoracic artery was routed through the transverse sinus and anastomosed to the marginal branch of the circumflex artery. The gastroepiploic artery was anastomosed to the right posterior descending coronary artery. In addition, an endarterectomy of the right coronary artery was performed because of severe right ventricular dysfunction during an attempt to wean the patient from extracorporeal circulation. However, after the operation the patient had a right ventricular infarction. Volume loading and inotropic support were necessary to wean the patient from the ventilator. Echocardiography revealed a dilated right ventricle with severely depressed systolic function. No pericardial effusion and no signs of intracavitary thrombus were present. He had a protracted clinical recovery. One month after admission he was discharged in stable condition. His medication consisted of bumetanide, digoxin, and aspirin $100 \mathrm{mg} /$ day.

Four weeks after discharge he was readmitted with severe exertional dyspnea (New York Heart Association class IV), tachypnea, and bilateral external jugular venous distention but no pulmonary or peripheral edema. The second heart sound was loud and variably split. The electrocardiogram demonstrated sinus tachycardia, left posterior hemiblock, and an incomplete right bundle branch block. Findings on the chest $x$-ray film were within normal limits. Repeated echocardiography revealed a persistently dilated right ventricle with improved systolic function and no signs of a thrombotic mass. A ventilation/ perfusion scan revealed extensive mismatch in both lungs compatible with a high probability for pulmonary embolism. Streptokinase was administered intravenously because of subsequent hemodynamic deterioration as a 